\title{
Visual Inspirations: The Pedagogical And Cultural Significance Of Creative Posters In The Art Classroom
}

Cindy Hasio, Valdosta State University, USA

\begin{abstract}
Creative posters in the classroom can inspire students to become engaged and motivated in learning art. Within the classroom, there are many places to put posters so that students can read them (especially when they get bored in the classroom) - on the cabinets, near the chalkboard, on the teacher's desk and any spare space on the wall.

There is cultural significance for using creative posters in the classroom; like advertising - the posters operate on a cultural level to provide symbolic associations between images, media figures, and values related to the student's lifestyle (Alperstein, 2003). Creating creative posters for a lesson, discussion, or example as part of this lesson helps students develop their critical thinking skills.
\end{abstract}

Keywords: Technology; Art Education; Critical Thinking; Student Learning; Pre-Service

\section{INTRODUCTION}

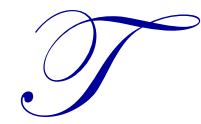

his article is written on how the pre-service art education students from the University of North Texas and Valdosta State University learned how to create unique and eye-catching posters that stimulated higher order thinking among their peers. The posters related to each student's world and showed a different culture that each student could connect with. The posters showed images, typography, colors and pictures that stimulated, inspired and motivated the students to learn about how they were influenced to become art educators and how they could influence their future students to learn about art in the classroom. One of the reasons why the author created this lesson was to also prepare students to use their posters once they start teaching their own class. The author felt it was important for them to learn how to initiate a discussion and promote motivation in the classroom, especially if their students are bored and staring at the wall. Posters would be a great way to catch their attention. It is important to train pre-service students to target their chosen grade level (kindergarten, middle school, and high school) and develop a concept that will connect with their students for more meaningful learning. The concept was the most important part for students to learn about how they could solve problems in a creative way and also stimulate the minds of their future students.

\section{Understand The Form And The Nature Of The Student's "Real World"}

One of the challenges was to get the students to think about what the message on their poster meant and how to provide images that would convey that message. How was it meaningful to them and how would it be meaningful to their students? Once students came up with an idea, they started to develop connections with ideas and images they thought would impact their future students. By sharing ideas with other students, they were on a collaborative level rather than a competitive level. Students thought more broadly and critically in interpreting and understanding the meanings behind their creative posters.

During the beginning process, students were first required to create thumbnail sketches that allowed them to visually communicate their ideas for their project. From this, there were one-on-one discussions with the students 
on what influenced them to choose their grade level and how their concepts would influence their own future students for inquiry and discussion. Through this assignment, it allowed the pre-students to discover their own strengths and ideas but also asking questions on how their posters would make a visual impact in relation to their concepts and how it would influence their students.

Allowing students to come up with concepts for images in their posters gave them a sense of identity. Some students remembered posters that influenced them when they were in the art classroom years ago. Their style and design were directly influenced by the students' lifestyle, environments, and personalities. In generating the overall meaning of their posters, there was always a narrative component. The symbolic association thus established brings the poster into a meaningful relationship with abstract values and ideas signified by the artifacts of daily life, creative ideas, and classroom environment (Botterill, Jhally, Kline, \& Leiss, 2005).

This lesson was also designed so that students could recognize the social, historical, and theoretical perspectives in areas such as the arts, humanities, sciences, and social sciences, and connect this with the creative process. The poster lesson created awareness for the subject and reflected what the students were most passionate and interested in. Included in this lesson was a rubric that had five categories for student assessment - Elements and Principles, Creativity and Originality, Effort and Perseverance, Craftsmanship, and Attitude/Responsibility.

\section{Using Technology To Construct Personal Meaning}

Their passion and interests helped them create unique images using graphic design programs. In the beginning of the class, students had problems creating the Creative posters because they had less experience with technology and felt anxiety and apprehension about learning these programs. Programs such as Illustrator and Photoshop were intimidating to some students because of the many different tools and techniques used to create something. However, the unlimited combinations of tools in these programs encouraged students to make the images more personalized, symbolic and representational. These programs are used in revolutionary ways to present new ways of representing and transforming images with extraordinary effects to convey their concepts (Fraga, 2000). Additionally, using technology attempts to represent the world with a continual deconstruction and reconstruction of our meaning of images (Betsky, 2001).

While creating their images, the students increased their proficiency for using the graphic design programs - Photoshop and Illustrator. They learned how to use the Internet as a source of information that helped them come up with concepts and ideas. Students also learned how to use scanners and edit their own digital pictures to use in their posters. As technology was used as a valuable tool for students to design their posters, it also engaged them in the process of making, creating, and producing objects and images that became visual culture for their future classrooms. Even though technology was used to help students develop their ideas, the process of creating was not solely based on technical skills. The skills that the students learned were to explore something meaningful that they can relate to their students and have them think deeper as they learn about visual culture and how it influences their daily lives. Technology integration was just another way for the students to construct their own knowledge and discover information on their own rather than just reading the textbook. Using these programs improved student learning to a higher degree in the class because they were constructing their knowledge by exchanging ideas and different techniques on how to use the program tools.

Emphasis for creating creative posters in the classroom as part of their online portfolio for applying for a job was another motivating factor for participation. This assignment helped prepare the students for entry into schools that required critical thinking skills, as well as technology skills, in the classroom. Through this, students were able to analyze, evaluate, and interpret diverse forms of the creative process and problem-solving through the interactions with their peers. Using technology through this creative posters assignment was just another way of problem-solving and self-reflection with different tools. Faced with the endless abundance of images, colors, and pictures from the internet, some students found it hard to focus on the creative posters as a medium of communication. As a result, many creative ideas and concepts were undermined and dominated by the great mass of visuals they used. This is why it was important to give feedback on a routine basis so that the students could concentrate on the main idea of getting their students to think on a higher level and getting them to inquire and ask questions from looking at their posters. 


\section{Creative Posters As A Real-World Context And A Cultural Story}

One way students came up with ideas for teaching higher order thinking was by using metaphors that could be easily understood by their target grade level. For example, one student wanted to teach her kindergarten class colors. She drew, scanned, and colored a sun made out yellow pencils and a cloud with paint buckets dripping different color paints through the cloud. She associated her concepts with weather so her students could remember the names of colors (see Figure 1).

A few students used the concept of careers in art for high school art students who planned to attend college and major in the art field. One student composed separate images to look like a comic strip. Since she had an admiration for comics growing up, she wanted her students to learn about different careers in comics and animation. By using various styles from different illustrators, she wanted her future high school students to see examples that were being used in the field of storyboarding (see Figure 2).

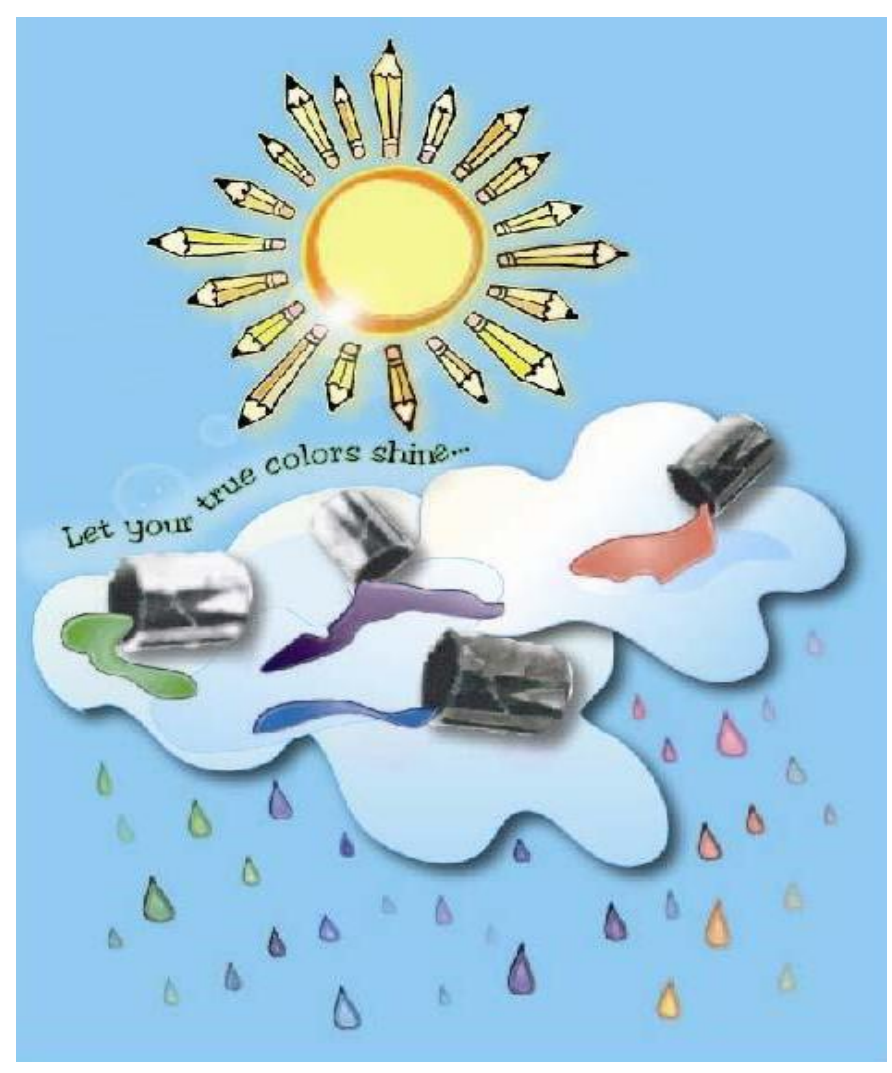

Figure 1: Student Created A Concept That Shows

Kindergarten Students Different Colors. This Poster Helps The Students Learn Colors By Using The Metaphor Of Clouds Dripping Colors Of Raindrops

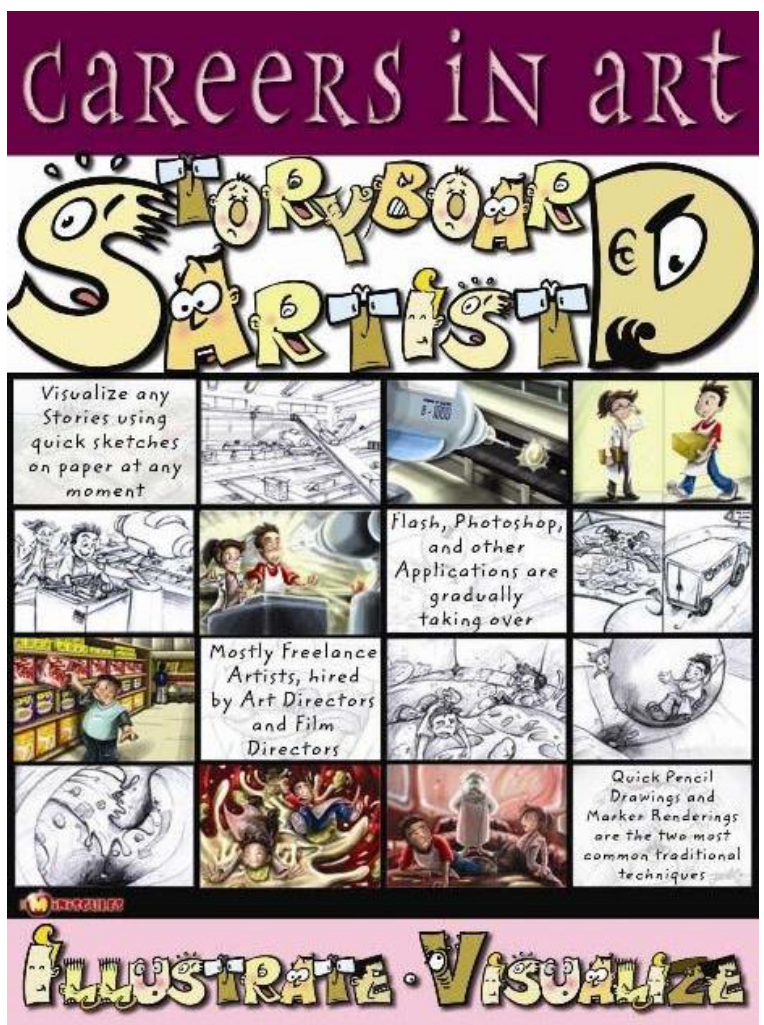

Figure 2: Student Work Describing A Career In Storyboarding. This Poster Shows High School Students How Different Types Of Illustration Can Be Used In Industries Such As Film, TV, Video, And Cartoons 
Another poster described a career in photography for high school students that conveyed the message of using photography to document societal issues and inspire social reconstruction (See Figure 3). She referenced photographer Dorothea Lange so that her students could inquire her and other photographers that inspired change through their work.

Other examples of student posters were created from the undergraduate students' art. They scanned their pictures and composed it in very creative ways so that they would be more meaningful to them and it would show their history as an art student transformed into an art educator. Using their own art as part of their visual composition also gave them a sense of ownership and confidence for others to ask them questions about how they developed their own artistic abilities. One student used the program Illustrator to integrate a lesson plan for middle school students, specifically those in underprivileged communities. In this poster, he encouraged students struggling with racism and identity within the African-American community to create art while listening to music. He also included reference to artist Romare Bearden so that students could see examples (see Figure 4).

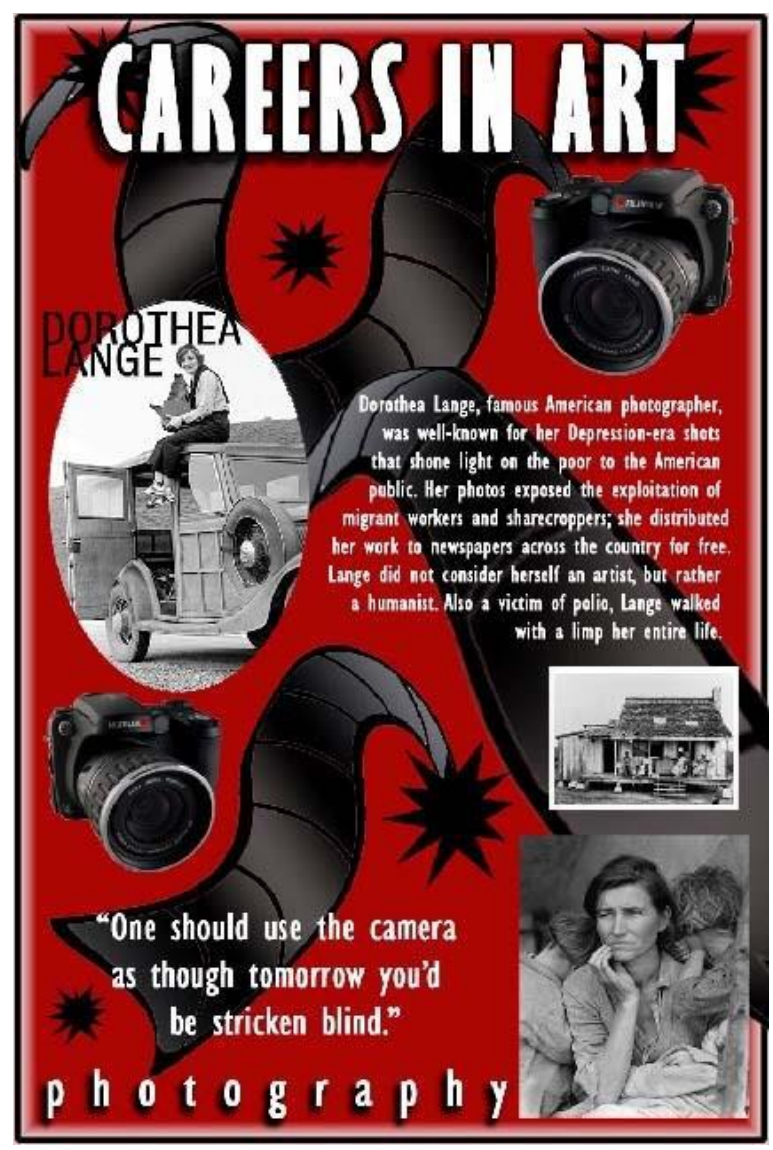

Figure 3: Student Work Describing A Career In Photography Shows High School Students How Photography Can Be Used To Reconstruct Social Issues

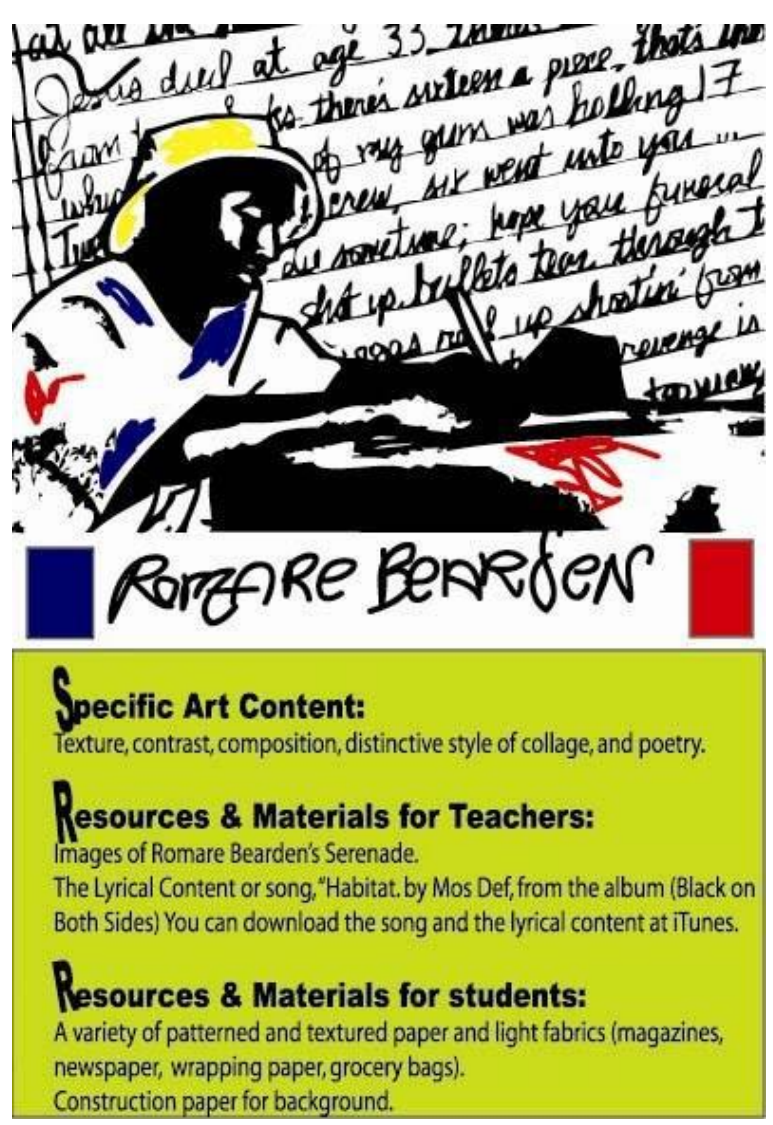

Figure 4: Student Work Describing How Music And Art Can Integrate. This Poster Shows Middle School Students In Underprivileged Schools How Art Can Assist Them In Expressing Their Struggles And Help Them Find Their Identities

Asking questions and feedback from others was important for the learning and development of the posters. In this class, students engaged in discussion and interpretations about the meaning of their poster concepts, targeting grade level during their process of artistic creation. The discussion process is important because it provides feedback on how to improve their ideas and how they can communicate a higher level of thinking from their students. It is important that students come up a statement or questions on their poster so that their future students could ask 
questions about what the message means in relationship to the picture. Constructing knowledge was a very collaborative effort when students asked their peers for feedback and ideas and it allowed students to synthesize what images influenced their life, classroom, and teaching experiences. After a while, students that developed a sense of self-confidence from becoming more proficient in the programs ended up taking their own initiative and helped others learn.

\section{CONCLUSION}

Teaching this class allowed the author to take a structuring role in students' learning processes and stimulate participation among them, as well as to share responsibility with them by being actively engaged and providing feedback. As a result, students improved their skills in critical thinking, their proficiency in using technology to make these posters, and they gained their sense of self-esteem in being able to create these posters. Incorporating this assignment into art instruction connects the curriculum to students' experiences and develops their knowledge and technology skills as teachers influenced from the visual world around them.

In general, the undergraduate students perceived technology as a complementary tool rather than replacing more traditional methods of artistic creation. Almost all the students cited the need for a new computer as a separate concern because of technical issues; however, the feelings of excitement, self-empowerment, optimism and determination were being expressed during their learning process. Most students commented on their satisfaction of successfully creating something in Photoshop and Illustrator that they could use in their own classrooms.

The most positive outcome of this class was the students' sense of self-empowerment from their finished work. Those who became self-empowered with their concepts and ideas produced higher quality posters to present their information and they developed a sense of pride in their work. Overall, the knowledge and skill outcomes reflected a higher level of processing and student learning. Students expressed themselves clearly and logically through their creative posters and demonstrated competence in problem-solving. They were also able to use their concepts to engage in self-reflection through class critiques and recognize that there were social, historical, and theoretical perspectives linked to their creativity.

\section{AUTHOR INFORMATION}

Dr. Cindy Hasio is an Assistant Professor in Art Education at Valdosta State University. Her focus is on community arts relating to connected knowing. Her current research describes how veterans empower themselves through the sharing and reflecting of their experiences within an arts and crafts environment. She has presented at the National Art Education Association, Georgia Art Education Association, Texas Art Education Association, and other conferences. She currently teaches art at community-based workshops in Valdosta, Georgia.

\section{REFERENCES}

1. Alperstein, N. M. (2003). Advertising in everyday life. Cresskill, NY: Hampton Press, Inc. Betsky, A. (2001). The age of recursive. In C. Coerver (Ed.) 010101: Art in technological times. San Francisco: San Francisco Museum of Modern Art.

2. Botterill, J., Jhally, S., Kline, S., \& Leiss, W. (2005). Social communication in advertising: Consumption in the mediated marketplace. (3rd edition). New York: Routledge Taylor \& Francis Group.

3. Fraga, T. (2000). Inquiry into allegorical knowledge systems for telematic art. In R. Asscott (Ed.) Art,technology, consciousness mind @large. Bristol, UK: Intellect Ltd. 
NOTES 